\title{
ASSESSMENT OF TRAFFIC FLOW ON ENUGU HIGHWAYS USING SPEED DENSITY REGRESSION COEFFICIENT
}

\author{
H. K. Ugwuanyi ${ }^{1}{ }^{*}$, F. O. Okafor ${ }^{2}$ and J. C. Ezeokonkwo ${ }^{3}$ \\ 1. Department of Civil EngineERIng, Michael OKPara Univ. of Agriculture, Umudike, Abia State, NigERIA \\ 2, 3, DEPARTMENT OF CiVIL ENGINEERING, UNIVERSITY OF NigERIA, NSUKKA, ENUGU STATE, NIGERIA \\ E-mail addresses: ${ }^{1}$ henrykene9@gmail.com, ${ }^{2}$ fidelis.okafor@unn.edu.ng, ${ }^{3}$ josephat.ezeokonkwo@unn.edu.ng
}

\begin{abstract}
In an attempt to estimate the operating speeds and volume of traffic on highway lanes as a function of predicted demands, speed-density models were estimated using data from highway sites. Speed, flow and volume are the most important elements of the traffic flow. In this study, the speed-density regression models are compared using five highways in relation to their correlation coefficient based on the daily traffic flow data obtained from the roads. The traffic flow data were collected by hourly traffic count on each road. The coefficient of correlation $(R)$ proved to have the best fit with a higher confidence and less variation for a two-lane highway than a one-lane highway. The space-mean speed (u) and density ( $k$ ) relationship for the two-lane highways are; $u=39.57-0.0025 k, u=58.67-0.01 k$, and $u=33.15-0.002 k$, whereas the space-mean speed $(u)$ and density $(k)$ relationship for the one-lane highways are; $u=$ $53.84-0.0016 k, u=29.76-0.003 k$ respectively. This research provides practical application for speed estimation, construction, maintenance and optimization of the highways using the speed-density models which will enhance traffic monitoring, traffic control management, traffic forecasting and model calibration.
\end{abstract}

Keywords: speed, density, flow, traffic count, correlation coefficient.

\section{INTRODUCTION}

Annual Average Daily Traffic, (AADT), is a measure used primarily in transportation planning and transportation engineering. Traditionally, it is the total volume of vehicle traffic of a highway or road for a year divided by 365 days. In 1992, American Association of State Highways and Transport Officials (AASHTO) released the AASHTO Guidelines for Traffic Data Programs which identified a way to produce an AADT without seasonal or day-of-week biases by creating an "average of averages" [1]. AADT is a useful and simple measurement of how busy the road is. Newer advances from traffic data providers are now providing AADT by side of the road, by day of week and by time of day. The presence of several hourly-congested highways forces researchers to better understand freeway operations under congested condition. The intelligent vehicle-highway system (like speed enforcement) programs will be able to function effectively if traffic behaviours under all conditions are modeled accurately [2].

Traffic flow in engineering is the study of interaction between vehicles, commuters and infrastructure (including the highways, signage and traffic control devices) with the aim of understanding and developing an optimal road network with efficient movement of traffic and minimal traffic congestion problems. The existing transportation facility which was originally designed and constructed to be adequate for the past traffic volume becomes practically inadequate to handle the present day traffic demand, resulting to an inevitable tremendous traffic congestion along the highway [3]. Most highways in Nigeria were designed without taking into consideration the daily traffic volume of the highway and the speed limits at necessary points along the highway. The tendency of the drivers to exceed the road design speed limits become prevalent leading to traffic accidents and conflicts. Thus, there is the need for $\mathrm{road} / \mathrm{highway}$ designers to use a valid model equation to help calibrate the speed limits in relation to the traffic density obtained at the section of the road.

The term traffic flow and volume are used interchangeably to define the number of vehicles that ply a particular road network at a given period of time. Queuing and delay occur in all congested situations; therefore a study on flow, speed and density on the roads would be relevant and necessitates a proper design of their intersection. 
The common approach proposed by most traffic flow researchers was using the density and speed data to calibrate the mathematical models and then convert them into speed flow model using Eq. (1):

$$
q=u k \text {. }
$$

In (1), $q$ is the traffic flow (veh/hr), which is the number of vehicles, $n$, passing some designated highway point in a time interval of duration, $t, u$ is the space-mean speed $(\mathrm{Km} / \mathrm{hr})$, which is the time necessary for a vehicle to traverse some known length of highway, L, and $k$ is the traffic density (veh/Km), which is the number of vehicles per unit length of roadway [4]. In this model, the density and speed data are obtained by using a special model vehicle (made for the purpose) that traverses the stated distance on the highway. The speed of the vehicle is recorded as it travels from one point of the highway to the other point under investigation.

The most intuitive starting point for developing a consistent, generalized traffic model is to focus on the relationship between speed and density [5]. To begin, consider a section of highway with only a single vehicle on it. Under these conditions, the density will be very low (veh $/ \mathrm{km}$ ) and the driver will be able to travel freely at a speed close to the design speed of the highway. This speed is referred to as the free-flow speed (denoted here as $\mathrm{u}_{f}$ ) because vehicle speed is not inhibited by the presence of other vehicles. As more and more vehicles begin to use a section of the highway, the traffic density will increase and the average operating speed of vehicles will decline from the free-flow value as drivers slow to allow for the maneuvers of others vehicles. Eventually, the highway section will become so congested (i.e. will have such a high density) that the traffic condition is referred to as 'come to a stop' ( $u=0$ ) and the density will be determined by the length of the vehicles and the spaces that drivers leave between them. This highdensity condition is referred to as the jam density, $\mathrm{k}_{\mathrm{j}}$.

There have been significant researches on the study of the speed-density and speed-flow models. In most models, the relationship of speed-flow or speed-density is dependent only on road type and a free flow speed. Researchers in many countries have investigated the relationship of the traffic flow, speed and density since 1934. In [6], the flow-density relationship of Canada using an extensive data set collected on the Queen Elizabeth Way in Ontario was studied. In [7] the regression model for the three variable relationships for Japanese cities was developed. Olszewski, et al [8] developed an area-wide traffic speed-flow model for the Singapore CBD to get an analytical framework for traffic management measures and evaluation. Lum, et al [9] analyzed the speed-flow relationship of the arterial road using the traffic volume and travel time data at a number of arterial roads in Singapore. Macroscopic stream models represent how the behaviour of one parameter of traffic flow changes with respect to another. Most traffic flows obeys the Poisson Model. The assumption of Poisson vehicle arrival also implies a distribution of the time interval between the arrivals of successive vehicle. Empirical observations have shown that the assumption of Poisson-distributed traffic arrivals is most realistic in highly congested traffic conditions [10].

A number of mathematical models between the traffic speed and density were proposed and calibrated by fitting curves to empirical traffic data. The results of these researches yielded many mathematical models.

The first traffic flow model was proposed by [11]. It suggested a linear relationship between the density and speed Eq. (2) expresses the relationship called the Green shield's model.

$$
\mathrm{u}=u f-\left[\frac{u_{f}}{k_{j}}\right] k
$$

Here, $u, k, u_{\mathrm{f}}$, and $k_{j}$ maintain their usual meaning. It indicates that when density becomes zero, speed approaches free flow speed (i.e. $\mathrm{u}=\mathrm{u}_{\mathrm{f}}$, when $K \rightarrow O$ ). In Greenshield's model, there exists an assumption of the relationship between speed and density which is difficult (if not impossible) to be obtained in the field. Hence, the validity of Green shield's model becomes questionable as it cannot be applied practically to field event.

Greenberg [12] proposed of a model using a fluid flow analogy and data from the Lincoln Tunnel in New York to establish a logarithmic relation between speed and density. This is called Greenberg's model as expressed by Eq. (3);

$$
u=u_{c} \ln \frac{k_{j}}{k}
$$

Where; $u_{c}$ is the speed at full traffic capacity, $k_{j}$ and $k$ are previously defined. This model has gained very good popularity because this model can be derived analytically (the derivation is out of the scope of this study). However, the main drawback of this model is that as density tends to zero, speed tends to infinity. This shows the inability of the model to predict the speeds at lower densities.

Underwood [13] hypothesized an exponential relationship between density and speed. The model is observed to generally have a better fit than the Greenshields and Greenberg models [12] for the uncongested traffic conditions, but does not present a good fit to the data for congested conditions. This model is called the Underwood model [13] as expressed by Eq. (4):

$$
u=u_{f} e^{-\frac{k}{k o}}
$$

Where, $u_{f}$ is the free flow speed and $k_{o}$ is the optimum density, i.e. the density corresponding to the maximum flow. In this model, speed becomes zero only when 
density reaches infinity which is the drawback of this model. Hence this cannot be used for predicting speeds at high densities.

Drake, et al [14] studied the various macroscopic traffic models postulated at that time and did not find any of them statistically significant. In developing his model, he estimated the density from speed and flow data, fitted the speed versus density function and transformed the speed versus density function to a speed versus flow function. The formulation of the [14] model is expressed by Eq. (5) and is called the Drake model:

$$
u=u_{f} \exp \left[-\frac{1}{2\left(\frac{k}{k c}\right)^{2}}\right]
$$

Where, $k_{c}$ is the density at capacity. His model generally yields a better fit than the above three models for uncongested conditions.

From the review above, it is obvious that most researchers focused on the character of the network roads, using traffic data generated by electronic counting machines without actually taking physical field traffic record, and lacking of comparisons of different road configurations. The researches were carried out mostly in the western world where road failures are rare and observation of traffic laws is held esteem, unlike in Nigeria that has a lot of the failed section of the highways and little or no observation to traffic laws. Hence, the postulated models above may be non-functional to Nigerian highways. In addition, many of the models were calibrated by using assumed and estimated values of the traffic data which is non-practical to field phenomenon. Some of them applied unattainable values to the traffic data, thus invalidating the postulated model.

This research paper is to compare the speed-density classical linear model to calibrate functional relationship based on the field recorded daily traffic data by a manual traffic count obtained from five (5) highways (with distinct number of lanes) in Enugu, Enugu State. So they represent two different kinds of roads being assessed by various traffic compositions.

\section{METHODOLOGY AND DATA COLLECTION}

\subsection{The Study Area.}

The data in this study were obtained from five (5) highways in Enugu, Enugu Sate. The roads include:

1. Enugu - 9 ${ }^{\mathrm{TH}}$ Mile Expressway (E9E)

2. Enugu - Abakaliki Expressway (EAE)

3. Enugu - Port Harcourt Expressway (EPE)

4. $9^{\text {th }}$ Mile - Onitsha Expressway (90E)

5. $9^{\text {th }}$ Mile - Oji-River Expressway (9ORE)

The locations of the two roads to be used for the full analysis are shown in the Figures 1 and 2 with a highlighter. These two roads are the representatives of the rest of the highways. Figure 1 is an aerial map of the communities close to the Enugu-9th Mile Expressway, with the road shown with a highlighter. The arrows pointing in both directions indicate that the road is a 2way highway. E9E has 2 lanes with the carriage width of $10 \mathrm{~m}$ average. It originated from New Market junction and goes through Gulf estate and continued its course to Onitsha. This highway is notorious for skidding away of heavy lorries and trailers/tanker, also head-on vehicular collision.

Figure 2 shows the aerial map of the towns surrounding Enugu-Abakaliki Expressway, with the road under study shown with dark highlighter indicating a two-way direction movement.

EAE has one lane of average width of $9.8 \mathrm{~m}$. It originated from Airport Road junction, goes through PRODA Headquarters and continued to Abakaliki.

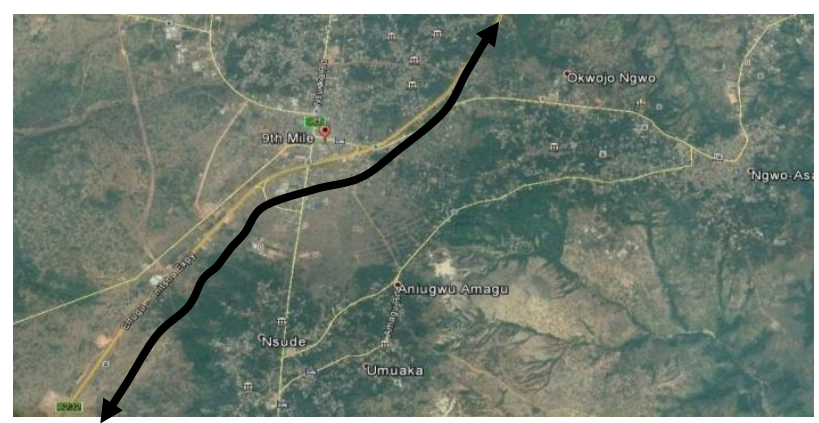

Figure 1: Map showing Enugu - 9th Mile Expressway

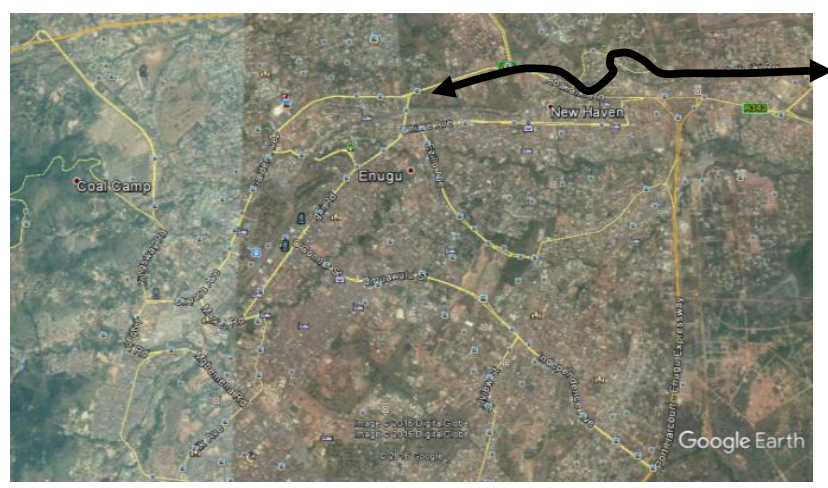

Figure 2: Map showing Enugu - Abakaliki Expressway

\subsection{Method of Data Collection}

Regression analysis was conducted based on the collected data by the road manual hourly traffic counters on the two highways. Fourteen (14) human recorders (counters) were stationed at Point A and Point B of $1 \mathrm{~km}$ distance of separation, seven (7) counters at one point on the road side, each counter recording one type of traffic composition. Each of the recorders was replaced by other recorders to avoid over-labour and fatigue. Then at the end of every hourly traffic record, the average of the volume of traffic composition at Points A and $\mathrm{B}$ is taken as the hourly traffic volume. The traffic 
count can be diagrammatically and mathematically expressed in the Figure 3.

Hourly daily traffic, $\mathrm{H}_{\mathrm{d}}$ is expressed by Eq. (6) as follows:

$$
H_{d}=\frac{\text { traffic Point } A+\text { traffic Point } B}{2}
$$

The time of record transition is taken to be one minutes of average lagging. We have seven traffic composition in consideration; 1. Motorcycle, 2. Tricycle, 3. Pickup/cars, 4. Mini buses, 5. Luxurious buses, 6. Lorry/trucks, 7. Tankers/trailers.

The hourly traffic count was done for seven consecutive days after which the summary of the count was recorded. Table 1 and 2 show the summary of the hourly traffic count collected from 07:00hrs - 19:00hrs (from Enugu 9th Mile Expressway and Enugu - Abakaliki Expressway respectively) for a period of seven consecutive days using Eq. (6) [15].

\subsection{Model Formulation and Calibration}

Using a linear relationship between space-mean speed and density, the model equation can be formulated as stated in Eqs. (7 - 10) respectively. Let

$$
y=a+b x
$$

Where: $y$ is the speed $(u), x$ is the density $(k), R$ is the correlation coefficient, $\mathrm{a}, \mathrm{b}$ is the constants to be determined.,

$$
\begin{gathered}
R=\frac{n \sum_{i=1}^{n} x y-\left(\sum_{i=1}^{n} x\right)\left(\sum_{i=1}^{n} y\right)}{\left[\sqrt { [ n ( \sum _ { i = 1 } ^ { n } x ^ { 2 } ) - ( \sum _ { i = 1 } ^ { n } x ) ^ { 2 } ) ] } \cdot \left[\sqrt{\left.\left[n\left(\sum_{i=1}^{n} y^{2}\right)-\left(\sum_{i=1}^{n} y\right)^{2}\right)\right]}\right.\right.} \\
b=\frac{\mathrm{n} \sum_{\mathrm{i}=1}^{\mathrm{n}} \mathrm{x}_{\mathrm{i}} \mathrm{y}_{\mathrm{i}}-\sum_{\mathrm{i}=1}^{\mathrm{n}} \mathrm{x}_{\mathrm{i}} \sum_{\mathrm{i}=1}^{\mathrm{n}} \mathrm{y}_{\mathrm{i}}}{\mathrm{n} \sum_{\mathrm{i}=1}^{\mathrm{n}} \mathrm{x}_{\mathrm{i}}-\left(\sum_{\mathrm{i}=1}^{\mathrm{n}} \mathrm{x}_{\mathrm{i}}\right)^{2}} \\
a=\bar{y}-b \bar{x}
\end{gathered}
$$

Where: $\bar{y}$ and $\bar{x}$ are the average values of $y$ and $x$ respectively

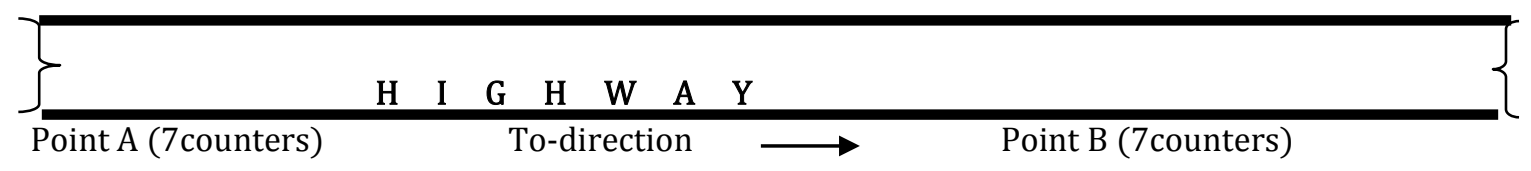

$\mathrm{L}=1 \mathrm{~km}$

\begin{tabular}{|c|c|c|c|c|c|c|c|c|}
\hline \multicolumn{9}{|c|}{$\begin{array}{l}\text { TRAFFIC COUNT TEMPLATE (SUMMARY SHEET) } \\
\text { COMMAND- RS9.1 ENUGU SECTOR COMMAND }\end{array}$} \\
\hline \multicolumn{9}{|c|}{ DIRECTION INDICATORS: TO } \\
\hline $\begin{array}{c}\text { TIME } \\
\text { INTERVAL }\end{array}$ & $\begin{array}{l}\text { DAY ONE } \\
21 / 09 / 2015\end{array}$ & $\begin{array}{l}\text { DAY TWO } \\
22 / 09 / 2015\end{array}$ & $\begin{array}{l}\text { DAY THREE } \\
23 / 09 / 2015 \\
\end{array}$ & $\begin{array}{l}\text { DAY FOUR } \\
24 / 09 / 2015\end{array}$ & $\begin{array}{l}\text { DAY FIVE } \\
25 / 09 / 2015\end{array}$ & $\begin{array}{c}\text { DAY SIX } \\
26 / 09 / 2015\end{array}$ & $\begin{array}{l}\text { DAY SEVEN } \\
27 / 09 / 15 \\
\end{array}$ & TOTAL \\
\hline $\begin{array}{c}0700- \\
0800 \mathrm{HRS}\end{array}$ & 459 & 297 & 291 & 252 & 297 & 320 & 162 & 2078 \\
\hline $\begin{array}{c}\text { 0801- } \\
\text { 0900HRS }\end{array}$ & 540 & 556 & 353 & 290 & 336 & 365 & 189 & 2629 \\
\hline $\begin{array}{c}0901- \\
1000 \mathrm{HRS}\end{array}$ & 358 & 424 & 455 & 312 & 370 & 380 & 189 & 2488 \\
\hline $\begin{array}{c}1001- \\
1100 \mathrm{HRS}\end{array}$ & 302 & 286 & 513 & 345 & 448 & 408 & 194 & 2496 \\
\hline $\begin{array}{c}1101- \\
1200 \mathrm{HRS}\end{array}$ & 272 & 251 & 453 & 339 & 459 & 527 & 179 & 2480 \\
\hline $\begin{array}{c}1201- \\
1300 \mathrm{HRS}\end{array}$ & 224 & 285 & 449 & 351 & 476 & 508 & 259 & 2520 \\
\hline $\begin{array}{c}1301- \\
1400 \mathrm{HRS}\end{array}$ & 259 & 334 & 451 & 414 & 495 & 450 & 297 & 2700 \\
\hline $\begin{array}{c}1401- \\
1500 \mathrm{HRS}\end{array}$ & 292 & 321 & 424 & 472 & 525 & 508 & 281 & 2823 \\
\hline $\begin{array}{c}1501- \\
1600 \mathrm{HRS}\end{array}$ & 304 & 332 & 436 & 493 & 534 & 544 & 302 & 2945 \\
\hline $\begin{array}{c}1601- \\
1700 \mathrm{HRS}\end{array}$ & 362 & 367 & 533 & 496 & 549 & 560 & 337 & 3204 \\
\hline $\begin{array}{c}\text { 1701- } \\
1800 \mathrm{HRS}\end{array}$ & 382 & 385 & 593 & 513 & 396 & 532 & 351 & 3152 \\
\hline $\begin{array}{c}1801- \\
1900 \mathrm{HRS}\end{array}$ & 354 & 328 & 473 & 524 & 351 & 380 & 235 & 2645 \\
\hline TOTAL & 4108 & 4166 & 5424 & 4801 & 5236 & 5482 & 2975 & 32160 \\
\hline
\end{tabular}

Figure 3: Diagrammatic representation of the traffic counting positions

Table 1: Traffic count done along Enugu - $9^{\text {th }}$ Mile Highway in accordance with the Road Safety Standard by the Federal Road Safety Corps, Enugu State Command, 2015. 
Table 2: Traffic count done along Enugu - Abakaliki Highway in accordance with the Road Safety Standard by the Federal Road Safety Corps, Enugu State Command, 2015.

\begin{tabular}{|c|c|c|c|c|c|c|c|c|}
\hline \multicolumn{9}{|c|}{ TRAFFIC COUNT TEMPLATE (SUMMARY SHEET) } \\
\hline & & & & & & & & \\
\hline \multicolumn{9}{|c|}{ DIRECTION INDICATORS: TO-DIRECTION } \\
\hline $\begin{array}{c}\text { TIME } \\
\text { INTERVAL }\end{array}$ & $\begin{array}{c}\text { DAY ONE } \\
23 / 12 / 2015\end{array}$ & $\begin{array}{l}\text { DAY TWO } \\
24 / 12 / 2015\end{array}$ & $\begin{array}{c}\text { DAY THREE } \\
25 / 12 / 2015\end{array}$ & $\begin{array}{l}\text { DAY FOUR } \\
26 / 12 / 2015\end{array}$ & $\begin{array}{c}\text { DAY FIVE } \\
27 / 12 / 2015\end{array}$ & $\begin{array}{c}\text { DAY SIX } \\
28 / 12 / 2015\end{array}$ & $\begin{array}{c}\text { DAY SEVEN } \\
29 / 12 / 2015\end{array}$ & TOTAL \\
\hline $\begin{array}{c}0700- \\
0800 \mathrm{HRS}\end{array}$ & 338 & 439 & 187 & 197 & 161 & 244 & 188 & 1754 \\
\hline $\begin{array}{c}0801- \\
0900 H R S\end{array}$ & 367 & 519 & 272 & 228 & 184 & 258 & 202 & 2030 \\
\hline $\begin{array}{c}\text { 0901- } \\
\text { 1000HRS }\end{array}$ & 418 & 546 & 310 & 173 & 203 & 260 & 253 & 2163 \\
\hline $\begin{array}{c}1001- \\
1100 H R S\end{array}$ & 447 & 577 & 252 & 227 & 235 & 277 & 206 & 2221 \\
\hline $\begin{array}{c}1101- \\
1200 \mathrm{HRS}\end{array}$ & 490 & 624 & 253 & 228 & 246 & 301 & 200 & 2342 \\
\hline $\begin{array}{c}1201- \\
1300 \mathrm{HRS}\end{array}$ & 552 & 714 & 253 & 204 & 272 & 307 & 208 & 2510 \\
\hline $\begin{array}{c}1301- \\
1400 \mathrm{HRS}\end{array}$ & 627 & 681 & 331 & 225 & 267 & 261 & 237 & 2629 \\
\hline $\begin{array}{c}1401- \\
1500 \mathrm{HRS}\end{array}$ & 628 & 693 & 419 & 222 & 271 & 235 & 240 & 2708 \\
\hline $\begin{array}{c}1501- \\
1600 \mathrm{HRS}\end{array}$ & 524 & 692 & 451 & 228 & 286 & 218 & 271 & 2670 \\
\hline $\begin{array}{c}1601- \\
1700 \mathrm{HRS}\end{array}$ & 661 & 699 & 448 & 243 & 286 & 213 & 287 & 2837 \\
\hline $\begin{array}{c}1701- \\
1800 \mathrm{HRS}\end{array}$ & 588 & 814 & 431 & 254 & 246 & 220 & 231 & 2784 \\
\hline $\begin{array}{c}1801- \\
1900 \mathrm{HRS}\end{array}$ & 553 & 681 & 349 & 194 & 234 & 130 & 189 & 2330 \\
\hline TOTAL & 6193 & 7679 & 3956 & 2623 & 2891 & 2924 & 2712 & 22785 \\
\hline
\end{tabular}

\subsection{Calculation of the Flow, Speed and Density.}

Traffic Flow, $q$, is simply defined as the number of vehicles, $n$, passing some designated highway point in a time interval of duration, $t$, as expressed by Eq. (11) as:

$$
q=\frac{n}{t}
$$

Here $\mathrm{q}$ is the traffic flow (veh/hr), $\mathrm{n}$ is the number of vehicles, $\mathrm{t}$ is the time interval (hr). Space - Mean Speed, $\mathrm{u}$, is the time necessary for a vehicle to traverse some known length of highway, L. If all vehicle speeds are measured over the same length of highway $\left(\mathrm{L}=\mathrm{L}_{1}=\mathrm{L}_{2}\right.$ $\left.=\ldots L_{n}\right)$, then $u$ is expressed as:

$$
\mathrm{u}=\left(\left(\frac{1}{n}\right) \sum_{i=1}^{n} \frac{1}{\left(L / t_{i}\right)}\right)^{-1}
$$

where, $\mathrm{L}=$ length of highway under study $(\mathrm{Km}), \mathrm{t}_{\mathrm{i}}=$ time interval of $\mathrm{i}^{\text {th }}$ vehicle (hr).

Traffic Density ( $k$ ) in veh/ $\mathrm{km}$ is defined by Eq. (13) as:

$$
k=\frac{n}{L}
$$

As usual, $n$ and $L$ maintain their usual meanings and units. In this paper, the Microsoft Excel Worksheet from Microsoft Office $2007^{\circledR}$ was employed in the calculation to aid in handling of large data and eliminates computation errors for computation of space-mean speed, $u$, length, $L$ of highway under study $=1 \mathrm{~km}$, Time interval, $(\mathrm{t})=1 \mathrm{hr}$ for the first sample record of traffic and $0.9833 \mathrm{hr}$ for the rest of the sample.

\section{RESULTS AND DISCUSSION}

\subsection{Enugu - 9th Mile Expressway (E9E).}

Using Day 6 (26-9-2015) for the computation, because it has the highest volume of daily traffic, $n=5482$ vehicles Computing in tabular form by using Microsoft Excel spread sheet from Table 1from Eqs.11, 12 and 13 respectively the traffic flow, $\mathrm{q}$, speed, $\mathrm{u}$ and density, $\mathrm{k}$ can be calculated on hourly basis as can be seen in Table 3 (for Enugu - 9th Mile) and Table 4 (for Enugu Abakaliki).

\subsection{Computation of Coefficient of Regression, ( $r$ or R).}

Denoting speed $(\mathrm{u})=y$, density $(\mathrm{k})=x, n=$ number of hourly sample $(n=12)$. From Table 4 , the values of the space-mean speed and density are imported from Table 3 above. Using statistical equation to create another table for the coefficient of correlation in an Excel Worksheet, the value of coefficient of correlation, $\mathrm{R}$ can be found. 
Table 3: Computation of Flow, Speed, and Density using Microsoft Excel Worksheet for E9E

\begin{tabular}{|c|c|c|c|c|c|c|c|c|c|c|}
\hline $\begin{array}{l}\text { Time } \\
\text { interval }\end{array}$ & $\begin{array}{c}\text { Volume, } \\
\text { n }\end{array}$ & $1 / \mathbf{n}$ & t(hrs) & $\mathbf{L}(\mathbf{k m})$ & $\begin{array}{c}\begin{array}{c}\text { Flow, } \\
\mathbf{q}=\mathbf{n} / \mathbf{t} \\
(\mathbf{v e h} / \mathbf{k m})\end{array} \\
\end{array}$ & $\begin{array}{c}\mathbf{L} / \mathbf{t} \\
(\mathbf{k m} / \mathbf{h r})\end{array}$ & $1 /(\mathrm{U} / \mathrm{t})$ & $\begin{array}{c}\mathbf{A}=\mathbf{1} / \mathbf{n} \mathbf{x} \\
\sum(\mathbf{1} /(\mathbf{L} / \mathbf{T}))\end{array}$ & $\begin{array}{c}\text { Space- } \\
\text { mean } \\
\mathbf{S} \text { peed, } \mathbf{U}= \\
\mathbf{L} / \mathbf{A}\end{array}$ & $\begin{array}{l}\text { Density, } \\
\mathbf{k}=\mathbf{n} / \mathbf{L}\end{array}$ \\
\hline $\begin{array}{l}\text { O700- } \\
\text { O80OHRS }\end{array}$ & 320 & 0.0031 & 1.0000 & 1 & 320 & 1.0000 & 1.0000 & 0.0369 & 27.0803 & 320 \\
\hline $\begin{array}{l}\text { O801- } \\
\text { O90OHRS }\end{array}$ & 365 & 27 & 0.9833 & 1 & 371 & 1.0169 & 9833 & 324 & 30.8885 & 365 \\
\hline \begin{tabular}{|l|}
$0901-$ \\
$1000 H R S$
\end{tabular} & 380 & 0.0026 & 0.9833 & 1 & 386 & 1.0169 & 0.9833 & 0.0311 & 32.1579 & 380 \\
\hline \begin{tabular}{|l}
$1001-$ \\
$1100 H R S$
\end{tabular} & 408 & 0.0025 & 0.9833 & 1 & 415 & 1.0169 & 0.9833 & .0290 & 34.5274 & 408 \\
\hline \begin{tabular}{|l|}
$1101-$ \\
$1200 H R S$
\end{tabular} & 527 & 019 & 0.9833 & 1 & 536 & 1.0169 & 0.9833 & 224 & 44.5979 & 527 \\
\hline & 508 & 0.0020 & 0.9833 & 1 & 517 & 1.0169 & 0.9833 & 0.0233 & 42.9900 & 508 \\
\hline $\begin{array}{l}1301- \\
1400 H R S\end{array}$ & 450 & 0.0022 & 0.9833 & 1 & 458 & 1.0169 & 0.9833 & 263 & 817 & 450 \\
\hline $\begin{array}{l}1401- \\
1500 H R S\end{array}$ & 508 & 0.0020 & 0.9833 & 1 & 517 & 1.0169 & 0.9833 & 0.0233 & 42.9900 & 508 \\
\hline \begin{tabular}{|l|}
$1501-$ \\
$1600 \mathrm{HRS}$ \\
\end{tabular} & 544 & 0.0018 & 0.9833 & 1 & 553 & 1.0169 & 0.9833 & 0.0217 & 46.0365 & 544 \\
\hline \begin{tabular}{|l|}
$1601-$ \\
$1700 H R S$
\end{tabular} & 560 & 0.0018 & 0.9833 & 1 & 569 & 1.0169 & 0.9833 & 0.0211 & 47.3906 & 560 \\
\hline \begin{tabular}{|l|}
$1701-$ \\
$1800 H R S$
\end{tabular} & 532 & 0.0019 & 0.9833 & 1 & 541 & 1.0169 & 0.9833 & 0.0222 & 45.0210 & 532 \\
\hline $\begin{array}{l}1801- \\
1900 H R S\end{array}$ & 380 & 0.0026 & 0.9833 & 1 & 386 & 1.0169 & 0.9833 & 0.0311 & 32.1579 & 380 \\
\hline SUM & 482 & & & & & & 11.8167 & & & \\
\hline
\end{tabular}

Table 4: Computation of correlation coefficient using Microsoft Excel Spreadsheet

\begin{tabular}{|c|c|c|c|c|c|}
\hline $\mathbf{n}$ & $\begin{array}{c}\text { Density (k) } \\
x \\
\end{array}$ & $\begin{array}{c}\text { Speed (u) } \\
y \\
\end{array}$ & $x^{2}$ & $y^{2}$ & $x y$ \\
\hline 1 & 320 & 27.0803 & 102400 & 733.3426 & 8665.696 \\
\hline 2 & 365 & 30.8885 & 133225 & 954.0994 & 11274.3025 \\
\hline 3 & 380 & 32.1579 & 144400 & 1034.1305 & 12220.002 \\
\hline 4 & 408 & 34.5274 & 166464 & 1192.1414 & 14087.1792 \\
\hline 5 & 527 & 44.5979 & 277729 & 1988.9727 & 23503.0933 \\
\hline 6 & 508 & 40.2820 & 258064 & 1622.6395 & 20463.256 \\
\hline 7 & 450 & 38.0817 & 202500 & 1450.2159 & 17136.765 \\
\hline 8 & 508 & 42.9900 & 258064 & 1848.1401 & 21838.92 \\
\hline 9 & 544 & 46.0365 & 295936 & 2119.3593 & 25043.856 \\
\hline 10 & 560 & 47.3906 & 313600 & 2245.8690 & 26538.736 \\
\hline 11 & 532 & 45.0210 & 283024 & 2026.8904 & 23951.172 \\
\hline 12 & 380 & 32.1579 & 144400 & 1034.1305 & 12220.002 \\
\hline SUM & 5482 & 461.2117 & 2579806 & 18249.9314 & 216942.98 \\
\hline AVERAGE & 456.8333 & 38.43430833 & & & \\
\hline
\end{tabular}

\begin{tabular}{|l|l|r|r|}
\hline & & & \\
\hline$n \sum x 2$ & & 30957672 & \\
\hline$n \sum y 2$ & $=$ & 218999.177 \\
\hline$n \sum x y$ & $=$ & 2603315.76 \\
\hline$\sum \times \sum y$ & $=$ & 2528362.539 \\
\hline
\end{tabular}

Using equation (8):

$$
\begin{gathered}
R=\frac{n \sum_{i=1}^{n} x y-\left(\sum_{i=1}^{n} x\right)\left(\sum_{i=1}^{n} y\right)}{\left[\sqrt { [ n ( \sum _ { i = 1 } ^ { n } x ^ { 2 } ) - ( \sum _ { i = 1 } ^ { n } x ) ^ { 2 } ) ] } \cdot \left[\sqrt{\left.\left[n\left(\sum_{i=1}^{n} y^{2}\right)-\left(\sum_{i=1}^{n} y\right)^{2}\right)\right]}\right.\right.} \\
\mathrm{R}=\frac{2603315.76-2528362.539}{\sqrt{\left[\left(30957672-(5482)^{2}\right)\right]} \cdot\left[\sqrt{\left[\left(218999.177-(461.2117)^{2}\right)\right]}\right]}=\frac{74953.221}{75420.5005}=0.9938
\end{gathered}
$$

To find the values of $a$ and $b$, using Microsoft Excel Worksheet for the computation;
Substitute in the equation $b=\frac{\mathrm{n} \sum_{\mathrm{i}=1}^{\mathrm{n}} \mathrm{x}_{\mathrm{i}} \mathrm{y}_{\mathrm{i}}-\sum_{\mathrm{i}=1}^{\mathrm{n}} \mathrm{x}_{\mathrm{i}} \sum_{\mathrm{i}=1}^{\mathrm{n}} \mathrm{y}_{\mathrm{i}}}{\mathrm{n} \sum_{\mathrm{i}=1}^{\mathrm{n}} \mathrm{x}_{\mathrm{i}}-\left(\sum_{\mathrm{i}=1}^{\mathrm{n}} \mathrm{x}_{\mathrm{i}}\right)^{2}}$

$$
\begin{array}{r}
\mathrm{b}=\frac{2587847.742-2513603.765}{65400-29702500}=-0.0025 \\
\mathrm{a}=\bar{y}-b \bar{x}=38.4343-(-0.0025 \times 454.1667)=39.57
\end{array}
$$

Therefore the model equation (from equation 10);

$$
u=a+b k==39.57-0.0025 k
$$


This value of $\mathrm{R}=0.9938$ shows a best fit of the data analysis and thus has a very high confidence and less variation of the traffic data. The Figure 4.1 shows the graph of space-mean speed against density for Enugu $9^{\text {th }}$ Mile Expressway. From the graph, as the density increases, the speed decreases because drivers slow down to allow for maneuvers of other vehicles. Consequently, when where there are very few vehicles along the highway, the density becomes very low and the drivers will be able to travel freely to a maximum speed. This maximum speed is referred to as free flow speed, $u_{f}$. From Figure $4.1 u_{f}=39.57 \mathrm{~km} / \mathrm{hr}$ when $\mathrm{k}=0$. This maximum value of speed is the design speed at that particular highway section.

\subsection{Enugu - Abakaliki Expressway.}

Using Day 2 (24-12-2015) for the computation, because it has the highest volume of daily traffic. As explained in section 3.1, the flow, space-mean speed and density can be calculated using the formulae in equations 11,12 and 13 respectively. Table 5 shows the values of the traffic parameters as computed using Microsoft Excel Worksheet 2007.

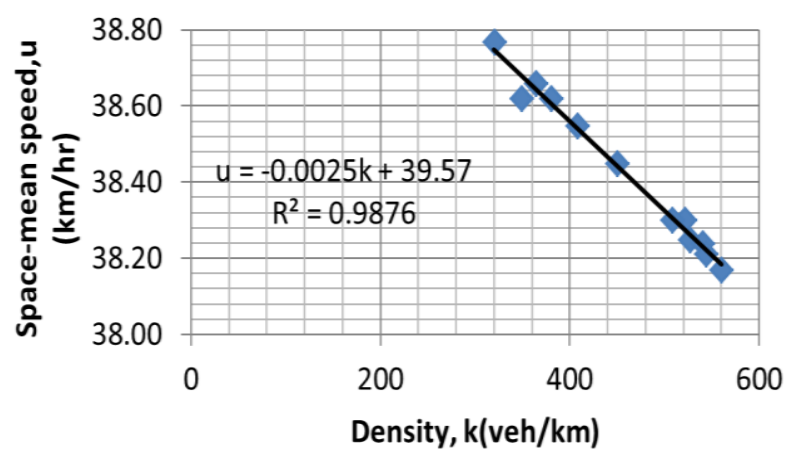

Fig. 4: Plot of Space-mean Speed versus Traffic Density for $E 9 E$

\subsection{Computation of Coefficient of correlation, ( $r$ or R).}

Denoting speed $(\mathrm{u})=y$, density $(\mathrm{k})=x, n=$ number of hourly sample $(n=12)$. Table 6 shows the statistical values of the computation for calculation of coefficient of correlation, R. Using equation (8) to calculate R.

Table 5: Analysis of Flow, Speed, Density using Microsoft Excel Worksheet for EAE

\begin{tabular}{|c|c|c|c|c|c|c|c|c|c|c|}
\hline \begin{tabular}{|l|} 
Time \\
interval
\end{tabular} & \begin{tabular}{|c|}
$\begin{array}{c}\text { Volume, } \\
\text { n }\end{array}$ \\
\end{tabular} & $1 / \mathbf{n}$ & t(hrs) & $\mathbf{L}(\mathbf{k m})$ & $\begin{array}{l}\text { Flow, } \\
q=n / t\end{array}$ & $L / t$ & $1 /(L / t)$ & $\begin{array}{c}A=1 / n x \\
\sum(1 /(L / T))\end{array}$ & $\underset{\text { L/A }}{\text { Speed, U }}=$ & $\begin{array}{l}\text { Density, } k \\
=n / L\end{array}$ \\
\hline \begin{tabular}{|l|}
$0700-$ \\
O800HRS
\end{tabular} & 439 & 0.0023 & 1.0000 & 1 & 439 & 1.0000 & 1.0000 & 0.0269 & 37.1508 & 439 \\
\hline \begin{tabular}{|l|} 
O801- \\
O9OOHRS
\end{tabular} & 519 & 0.0019 & 0.9833 & 1 & 528 & 1.0169 & 0.9833 & 0.0228 & 43.9209 & 519 \\
\hline \begin{tabular}{|l|} 
O901- \\
$1000 H R S$
\end{tabular} & 546 & 0.0018 & 0.9833 & 1 & 555 & 1.0169 & 0.9833 & 0.0216 & 46.2058 & 546 \\
\hline \begin{tabular}{|l|}
$1001-$ \\
$1100 \mathrm{HRS}$
\end{tabular} & 577 & 0.0017 & 0.9833 & 1 & 587 & 1.0169 & 0.9833 & 0.0205 & 48.8292 & 577 \\
\hline \begin{tabular}{|l|}
$1101-$ \\
$1200 H R S$
\end{tabular} & 624 & 0.0016 & 0.9833 & 1 & 635 & 1.0169 & 0.9833 & 0.0189 & 52.8066 & 624 \\
\hline \begin{tabular}{|l|}
$1201-$ \\
$1300 \mathrm{HRS}$ \\
\end{tabular} & 654 & 0.0015 & 0.9833 & 1 & 665 & 1.0169 & 0.9833 & 0.0181 & 55.3454 & 654 \\
\hline \begin{tabular}{|l|}
$1301-$ \\
$1400 H R S$
\end{tabular} & 681 & 0.0015 & 0.9833 & 1 & 693 & 1.0169 & 0.9833 & 0.0174 & 57.6303 & 681 \\
\hline \begin{tabular}{|l|}
$1401-$ \\
$1500 H R S$ \\
\end{tabular} & 693 & 0.0014 & 0.9833 & 1 & 705 & 1.0169 & 0.9833 & 0.0171 & 58.6458 & 693 \\
\hline \begin{tabular}{|l|}
$1501-$ \\
$1600 H R S$ \\
\end{tabular} & 692 & 0.0014 & 0.9833 & 1 & 704 & 1.0169 & 0.9833 & 0.0171 & 58.5612 & 692 \\
\hline \begin{tabular}{|l|}
$1601-$ \\
$1700 H R S$ \\
\end{tabular} & 699 & 0.0014 & 0.9833 & 1 & 711 & 1.0169 & 0.9833 & 0.0169 & 59.1536 & 699 \\
\hline \begin{tabular}{|l|}
$1701-$ \\
$1800 H R S$ \\
\end{tabular} & 685 & 0.0015 & 0.9833 & 1 & 697 & 1.0169 & 0.9833 & 0.0173 & 57.9688 & 685 \\
\hline \begin{tabular}{|l|}
$1801-$ \\
$1900 H R S$ \\
\end{tabular} & 870 & 0.0011 & 0.9833 & 1 & 885 & 1.0169 & 0.9833 & 0.0136 & 73.6246 & 870 \\
\hline SUM & 7679 & & & & & & 11.8167 & & & \\
\hline
\end{tabular}

Table 6: Computation of regression coefficient using Microsoft Excel Spreadsheet

\begin{tabular}{|c|c|c|c|r|r|}
\hline & DENSITY(k) & SPEED(u) & & & \\
& $\mathrm{x}$ & $\mathrm{y}$ & $x^{2}$ & $y^{2}$ & \multicolumn{1}{c|}{$x y$} \\
\hline 1 & 439 & 37.1508 & 192721 & 1380.1819 & 16309.2012 \\
\hline 2 & 519 & 43.9209 & 269361 & 1929.0455 & 22794.9471 \\
\hline 3 & 546 & 46.2058 & 298116 & 2134.9760 & 25228.3668 \\
\hline 4 & 577 & 48.8292 & 332929 & 2384.2908 & 28174.4484 \\
\hline 5 & 624 & 52.8066 & 389376 & 2788.5370 & 32951.3184 \\
\hline 6 & 654 & 55.3454 & 427716 & 3063.1133 & 36195.8916 \\
\hline 7 & 681 & 57.6303 & 463761 & 3321.2515 & 39246.2343 \\
\hline 8 & 693 & 58.6458 & 480249 & 3439.3299 & 40641.5394 \\
\hline 9 & 692 & 58.5612 & 478864 & 3429.4141 & 40524.3504 \\
\hline 10 & 699 & 59.1536 & 488601 & 3499.1484 & 41348.3664 \\
\hline 11 & 685 & 57.9688 & 469225 & 3360.3818 & 39708.628 \\
\hline 12 & 870 & 57.6303 & 756900 & 3321.2515 & 50138.361 \\
\hline & & & & & \\
\hline SUM & 7679 & 633.8487 & 5047819 & 34050.9216 & 413261.653 \\
\hline AVERAGE & 639.9167 & 52.820725 & & & \\
\hline
\end{tabular}

$$
\mathrm{R}=\frac{12(413261.653)-(7679 \times 633.8487)}{\left[\sqrt{\left.[12(5047819)-7679)^{2}\right]}\right] \times\left[\sqrt{\left[12(34050.9216)-(633.8487)^{2}\right]}\right]}=\frac{91815.6687}{104887.9638}=0.8753
$$


To find $a$ and $b$ using equations (8) and (9), substitute in equation (9),

$$
b=\frac{4959139.836-4867324.167}{92148-58967041}=-0.0016 .
$$

$a=\bar{y}-b \bar{x}=52.8207-(-0.0016 \times 639.9167)=53.84$

Therefore the model equation is;

$$
u=53.84-0.0016 k
$$

Figure 5 shows the graph of space-mean speed against density for Enugu - Abakaliki Expressway. From the graph, it can be observed that the there is a little variation in the traffic data. As the density increases, the speed decreases because the drivers allow for the safe maneuver of other speeding vehicles. The free flow speed when the density is zero is $\mathrm{u}_{f}=47.13 \mathrm{Km} / \mathrm{hr}$. this is the design speed of the highway which must not be exceeded at the section of the highway. At a certain point in the graph, the speed drops drastically due to the influx of vehicles trying to pass the highway section at the same time.

From the calibrated equation (14), $\mathrm{u}=38.38-0.0025 \mathrm{k}$ for E9E, and equation (15), $\mathrm{u}=53.84-0.0016 k$ for $\mathrm{EAE}$, as the traffic density increases, the space-mean speed decreases, and vice versa. It shows that when there are few vehicles on a highway, the vehicles tend to maximize the design speed of the road which is limited to a certain value. This is in contrast to the findings of other researchers which asserted that at a very low density, the speed tends to infinity which is not realistic in the field. The limitation of speed level to a maximum value rather than infinity is as a result of the effect of field phenomena like merging/diverging traffic, breakdown of vehicle that suddenly comes to a stop, traffic joining the highway from a minor road, commercial vehicles/tricycles braking to pick or drop passengers and so on. Table 7 shows traffic data differences of the two roads under study, indicating the jam density $\left(k_{\mathrm{j}}\right)$ and the free flow speed $\left(u_{\mathrm{f}}\right)$

The quantity $R$, called the linear correlation coefficient, measures the strength and the direction of the linear relationship between space-mean speed and traffic density. Since the correlation is greater than 0.8 , it is generally described as strong. The coefficient of determination, $R^{2}$, gives the proportion of the variance (fluctuation) of space-mean speed that is predictable from the density. The coefficient of determination represents the percent of the data that is the closest to the line of best fit. For E9E, $R^{2}=0.9876$, means that $98.76 \%$ of the total variation in speed can be explained by the linear relationship between density and speed (as described by the regression equation). The other $1.24 \%$ of the total variation in speed indicates the diverted/merged traffic after/before being counted at one point of traffic counting position. For EAE, $\mathrm{R}^{2}=$ 0.7662 , means that $76.62 \%$ of the total variation in speed can be explained by the linear relationship between density and speed. The other $23.38 \%$ of the total variation in speed indicates the diverted/merged traffic after/before being counted at one point of traffic counting position. This is an indication that more vehicles diverge to or merge from other service roads than on the E9E.

It was also observed that the Enugu - $9^{\text {th }}$ Mile Expressway has a higher value of $\mathrm{R}$, (best fit) and high confidence but has a lower value of the speed - density relationship than the Enugu - Abakaliki Expressway. This is because of the differences in the structure and the traffic composition of the two highways.

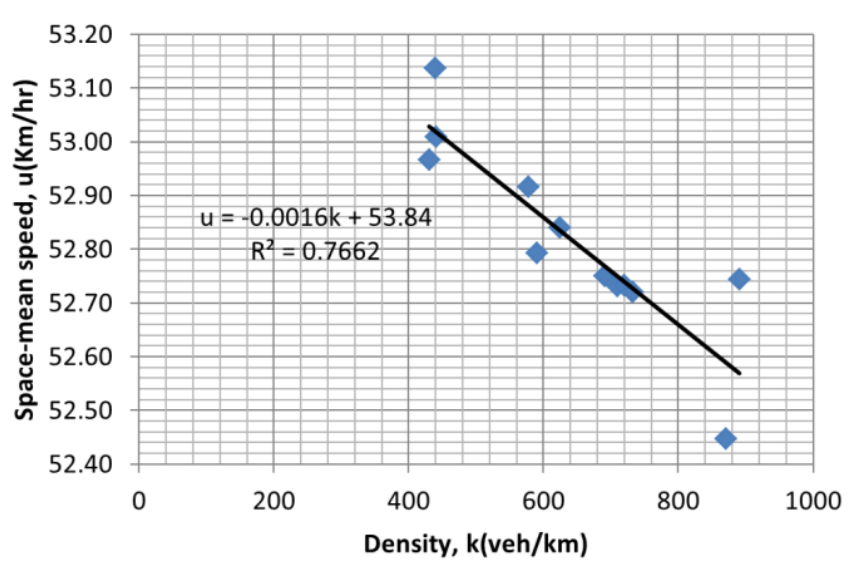

Figure 5: Plot of Space-mean Speed (u) against Traffic Density (k) for EAE

Table 7: Traffic data values for E9E and EAE

\begin{tabular}{ccccccc}
\hline $\begin{array}{c}\text { Name of } \\
\text { Road }\end{array}$ & $\begin{array}{c}\text { Number of } \\
\text { Lanes }\end{array}$ & $\begin{array}{c}\text { Correlation } \\
\text { Coefficient, } R\end{array}$ & $\begin{array}{c}\text { Coefficient Of } \\
\text { Determination, } R^{2}\end{array}$ & Model Equation & $\begin{array}{c}\text { Jam Density, } \\
\text { (veh/km) } k_{\mathrm{j}}\end{array}$ & $\begin{array}{c}\text { Free Flow } \\
\text { Speed, (Km/hr) } \\
U_{\mathrm{f}}\end{array}$ \\
\hline E9E & 2 & 0.9938 & 0.9878 & $\mathrm{u}=38.32-0.0025 \mathrm{k}$ & 15,328 & 38.32 \\
EAE & 1 & 0.8753 & 0.7662 & $\mathrm{u}=53.84-0.0016 \mathrm{k}$ & 33,650 & 53.84 \\
\hline
\end{tabular}


Table 8: Traffic data values for EPE, 9OE, and 9ORE

\begin{tabular}{ccccccc}
\hline $\begin{array}{c}\text { Name of } \\
\text { Road }\end{array}$ & $\begin{array}{c}\text { Number of } \\
\text { Lanes }\end{array}$ & $\begin{array}{c}\text { Correlation } \\
\text { Coefficient, } R\end{array}$ & $\begin{array}{c}\text { Coefficient of } \\
\text { Determination, } R^{2}\end{array}$ & Model Equation & $\begin{array}{c}\text { Jam Density, } \\
\left(\text { veh/km) } \mathrm{kj}_{\mathrm{j}}\right.\end{array}$ & $\begin{array}{c}\text { Free Flow Speed, } \\
(\mathrm{Km} / \mathrm{hr}) \mathrm{U}_{\mathrm{f}}\end{array}$ \\
\hline EPE & 2 & 0.9818 & 0.9757 & $u=58.67-0.01 k$ & 5,867 & 58.67 \\
9OE & 2 & 0.9746 & 0.9498 & $u=33.15-0.002 k$ & 16,575 & 33.15 \\
$9 \mathrm{ORE}$ & 1 & 0.8651 & 0.7483 & $u=29.76-0.003 k$ & 9,920 & 29.76 \\
\hline
\end{tabular}

E9E is a two-lane highway with various dilapidated points and conflicts/accident prone zones, comprising mostly of heavy duty trucks and lorries, which as a result of the nature of the road, travel at a lower speed. This is evidence to the reduced value of the space-mean speed of traffic as many vehicles try to maneuver from one lane to the other. EAE is a one-lane highway with little number of pot holes and conflict zones. The value of $\mathrm{R}$ is lower because of frequent stopping, diverging and merging (from other minor roads) of commercial vehicle passing through a section of the highway to serve their passengers. It was also observed that the hourly traffic flow is higher on EAE than on E9E as can be seen in Table 7. This is due to some road users having alternatives to the use of E9E.

Similar work done for Enugu - Port Harcourt Expressway (EPE), 9 ${ }^{\mathrm{TH}}$ Mile - Onitsha Expressway (90E), and 9 ${ }^{\mathrm{TH}}$ Mile Oji River Expressway (90RE) yielded the following results as shown in Table 8. It shows that EPE and 9OE have close traffic characteristic as compared to E9E because they are all two-lane highways. Similarly, 90RE has traffic characteristic very close to EAE because it is also a one-lane highway. In this regard, E9E and EAE become the representatives of the two forms of the highways under study.

\section{CONCLUSION}

The analysis of the traffic study using the speed-density regression model carried out above revealed that the twolane highways have a better fit of correlation coefficient than the one-lane highways. The calibrated speed-density model showed that the one-lane highways have higher values of the traffic data for space-mean speed with less variation than the two-lane highways. It can also be observed that the characteristics of the two-lane highway and one-lane highway are different, and the relations of their three traffic flow factors (flow, speed and density) are also different. The decrease of speed in relation to the increase in the traffic density is seen to conform to those in the literature but is contrary to the earlier model that stipulated an infinite speed at a very low density.

This research therefore provides a good approximation necessary for use in the calibration of speed along a highway section in cognizance of diverging/merging traffic from minor service roads. It is also found useful for use in speed control device and law enforcement for overspeeding drivers.

\section{REFERENCES}

[1] AASHTO Guidelines for Traffic Data Programs. American Association of State Highway and Transportation Officials. 1992.

[2] Kemal, Seluc Ögüt. An Alternative Regression Model of Speed-Occupancy Relation at the Congested Flow Level. The Bulletin of the Istanbul Technical University, 1-2. 2004.

[3] Ezeokonkwo, J. C . Methods of Flexible Pavement Design. (Unpublished Lecture note), University of Nigeria, Nsukka, Nigeria. 2015.

[4] Zhaoyang, L. U. and Qiang, M.E.N.G. .Analysis of Traffic Speed-Density Regression Models -A Case Study of Two Roadway Traffic Flows in China. Proceedings of the Eastern Asia Society for Transportation Studies, Vol.9, 2013: 3-4. 2013.

[5] Fred L. Mannering, Walter P. Kilareski Principles of Highway Engineering and Traffic Analysis, Second Edition. USA: John Wiley \& Sons. pp 143-145. 1998.

[6] Hall, F.L., Allen, B.L., Gunter, M. A. Empirical Analysis of Freeway Flow-Density Relationships. Transportation Research Part A: General 20(3), 197-210. 1986.

[7] Ohta, K., Harata, N. Properties of aggregate speed-flow relationship for road networks, Proc. 5-th World Conference on Transport Research, Yokohama, Japan, pp. 451-462. 1989.

[8] Olszewski, P., Fan, H.S.L., Tan, Y.-W. Area-wide traffic speed-flow model for the Singapore CBD. Transportation Research Part A: Policy and Practice 29(4), 273-281. 1995.

[9] Lum, K., Fan, H., Lam, S., Olszewski, P. Speed-Flow Modeling of Arterial Roads in Singapore. Journal of Transportation Engineering124 (3), 213-222. 1998.

[10] Okafor, F. 0. Traffic Arrival Interval. (Unpublished Lecture note), University of Nigeria, Nsukka, Nigeria. 2015.

[11] Greenshields, B. D. A Study of Traffic Capacity. Highway Research Board14, 448-477. 1935.

[12] Greenberg, H. An Analysis of Traffic Flow. Operations Research7, 79-85. 1959.

[13] Underwood, R. T. Speed, volume, and density relationships: Quality and Theory of Traffic Flow. Proceedings of the Eastern Asia Society for Transportation Studies, Vol.9, 2013. Yale Bureau of Highway Traffic, 141188. 1961.

[14] Drake, L. S., Schofer, J. L., May, A.D. A Statistical Analysis of Speed-Density Hypotheses. Highway Research Record 154, 53-87. 1967.

[15] Federal Road Safety Corps. Policy Research \& Statistics. Federal Road Safety Corps, Enugu Sector Command, 2015. 